Cancer chemotherapy

\title{
DNA amplification and multidrug resistance
}

from Piet Borst

SINCE 1978, when Robert Schimke and his co-workers showed that it could be associated with the development of drug resistance in eukaryotic cells ${ }^{1}$, gene amplification has been shown to underlie resistance to several drugs and toxic compounds in a variety of eukaryotic cells, including such unicellular organisms as fungi and protozoa (see ref. 2 for an excellent recent review). There have also been hints that it underlies another form of drug resistance in mammalian cells - the intriguing multidrug resistance (or pleiotropic drug resistance) in which the induction of resistance to one drug leads to crossresistance to a motley assembly of other drugs with widely different chemical structures and cellular targets ${ }^{2-6}$. Direct evidence that multidrug resistance is due to gene amplification has been missing. That lacuna is filled by the paper of Roninson $e t$ $a l$. on page 626 of this issue ${ }^{7}$.

Schimke's studies were on the development of resistance to methotrexate (MTX), an inhibitor of the enzyme dihydrofolate reductase (DHFR). Resistance to it can arise in at least three ways ${ }^{3,4}$ : by a decrease in the carrier-mediated uptake of MTX; by the production of an altered DHFR; and by the increased production of normal DHFR. Schimke and co-workers showed that the third route involves an amplification of the structural gene for DHFR!

How does the genome know that DHFR has been blocked by MTX? The answer seems to be simple: MTX inhibits cellular DNA synthesis; when the block is released by removal of the drug, chromosome segments that have partially replicated will not only continue the old replication round but also re-replicate, producing an extra copy of that region. Once gene amplification is underway, selection with MTX ensures that cells with the largest number of copies of the DHFR gene will have the best chance of surviving. By stepwise increase of the drug concentration, one can eventually obtain cells with many copies of the gene. (For more on the relationship between amplification and replication the reader is referred to David Denhardt's article in these columns last week ${ }^{8}$.)

The extra gene copies produced by amplification may either be re-inserted back into chromosomes to yield homogeneously staining regions (HSRs) or remain as extra 'minute' chromosomes, often found in pairs as double minutes. HSRs are stable when cells are grown without drug, but maintenance of double minutes usually requires continuing drug selection because they lack a centromere. Random distribution of double minutes among daughter cells and loss to the cytoplasm rapidly leads to the emergence of cells that have lost most or all of their double minutes; this instability is a hallmark of drug resistance due to this type of gene amplification (see refs 2, 9-11).

The presence of double minutes in multidrug-resistant cells, as well as the unstable nature of multidrug resistance, has strongly indicated that this, too, is due to gene amplification ${ }^{12,13}$. Resistance of this type can be induced with colchicine, a drug that prevents tubulin polymerization, or with one of the carcinostatic anthracyclines, drugs with diverse effects on cells. Crossresistance develops to a group of drugs whose only features in common are a molecular weight between 350 and 1,250 and an amphiphilic aromatic nature. This indicates that multidrug resistance is due to altered drug transport, but whether the mutation results in decreased drug entry, increased efflux or a combination of these mechanisms is still not certain ${ }^{2-5}$.

A corollary of this type of drug resistance is the overproduction of a large membrane glycoprotein with a molecular weight around 170,000 . A reasonable hypothesis is that this membrane glycoprotein is encoded in the amplified DNA ${ }^{13}$. This cannot be the whole story, however, because different multidrug-resistant cell lines show different degrees of cross-resistance to individual drugs.

The direct evidence for gene amplification in multidrug resistance provided by Roninson et al. in this issue of Nature comes from the use of an elegant, in-gel, renaturation technique. The authors show that two multidrug-resistant Chinese hamster cell lines contain amplified DNA segments, absent in revertants. They have cloned one of the amplified segments as recombinant DNA in Escherichia coli and show that the degree of drug resistance correlates with the number of copies of this segment in the DNA of resistant cells. The two cell lines have different patterns of cross-resistance, and it is therefore of interest that the two lines have only part of the amplified DNA segments in common. This suggests that at least three proteins can contribute to multidrug resistance: one preferentially induced by anthracylines, one by colchicine and one induced both by anthracyclines and by colchicine. It should not be too long before the gene products of these amplified genes have been identified.

What is the relevance of this sophisticated molecular biology to the clinician treating cancer patients? Only limited information is available to answer this question.
Amplification of the gene for DHFR has been shown to occur in tumour cells from patients who have had prolonged treatment with MTX ${ }^{14-18}$. Multidrug resistance is frequently observed in patients, but whether gene amplification contributes to it is not known. Once the amplified genes in multidrug-resistant human cell lines have been cloned it should be easier to test for amplification of these genes in tumour biopsies by standard molecular and cytological hybridization techniques. I expect that these experiments will give positive results in a significant fraction of patients exposed to intensive treatment with carcinostatic drugs. Most carcinostatic drugs block DNA replication; some of these drugs act on DNA in a similar fashion to certain carcinogens which are among the most effective inducers of gene amplification 1, 19-21; and the schedules of drug administration used by clinicians are not incompatible with induction of gene amplification.

If gene amplification is important for clinical multidrug resistance, a more complete understanding of the phenomenon might be useful. Knowledge of which gene is amplified could allow prediction of cross-resistance to other drugs. Knowledge of the detailed mechanism of drug exclusion could lead to the design of modified drugs not affected by the exclusion mechanism. The membrane proteins overproduced could form useful targets for antibody-coupled toxins. Multidrug resistance is obviously an area where gene amplification will induce research amplification.

. Schimke, R.T., Alt, F.W., Kellems, R.E., Kaufman, R. \& Bertino, J R Cold Spring Harb. Symp. quant. Biol 42,649 (1978).

2. Stark, G.R. \& Wahl, G.M. A. Rev. Biochem. 53, 447 (1984)

3. l.ing, V. Drug and Hormone Resistance in Neoplasia (cds Bruchovsky, N. \& Goldie, J.H.) I (CRC. Florida, 1982).

4. Jolivet, J., Curt, G.A., Clendeninn, N.J., Yeh, G.C. \& Chabner, B.A. Chemotherapy 1983, The EORTC Cancer Chemotherapy Annual no.5 (eds Pinedo, H.M. \& Chabner, B.A.) 1 (Elsevier, Amsterdam, 1983)

5. Chabner, B.A., Clendeninn, N.J. \& Curt, G.A. Cancer Treat. Rep. 67, 855 (1983).

6. Biedler, J.L. \& Peterson, R.H.F. Molecular Action and Targets for Cancer Chemotherapeutic Agents (eds SarIorelli, A.C., Lazo, J.S. \& Bertino, J.R.) 455 (Academic, London, 1981).

7. Roninson, I.B., Abclson, H.T., Housman, D.E., Howell, N. \& Varshavsky, A. Nature 309, $626(1984)$

. Denhardt, D.T. Nature 309, $515(1984)$

9. Schimke, R.T. (ed.) Gene Amplification (Cold Spring Harbor Laboratory, New York, 1982)

10. Cowell, J.K. A. Rev. Genet. 16. 21 (1982).

11. Fox, M. Nature 307, 212 (1984).

12. Baskin, F., Rosenberg, R.N. \& Dev, V. Proc. natn. Acad. Sci. U,S.A. 78, 3654 (1981)

13. Robertson, S.M., ling, V. \& Stanners, C.P. Molec. cell. Biol. 4, 500 (1984)

4. Curt, G.A. et al. New Engl. J. Med. 308, 199 (1983).

15. Shoemaker R.H. Curt, G.S. \& Carney, D.N. Cancer Treat. Rep. 67, 883 (1983).

6. Bertino, J.R. Cancer Treat. Rep. 67, 901 (1983).

17. Chabner, B.A., Clendeninn. N.J. \& Curt, G.A. Cancer Treat. Rep. 67, 855 (1983).

18. Curt, G.A., Cowan, K.H. \& Chabner, B.A. J. clin. Oncol. $2,62(1984)$.

19. L.avi, S. Proc natn. Acad. Sci. U.S.A. 78, 6144 (1981).

20. Lavi, S. J. cell. Biochem. 18, 149 (1982).

21 Lavi, S. Kohn, N Kleinberger, T., Berko, Y. \& Etkin, S UCLA Symp. molec. cell. Biol. 11, 659 (1983).

Piet Borst is at the Nederlands Kanker Instituut, Plesmanlaan 121, 1066 CX Amsterdam, The Netherlands. 